Supplement of Hydrol. Earth Syst. Sci. Discuss., 11, 12799-12831, 2014

http://www.hydrol-earth-syst-sci-discuss.net/11/12799/2014/

doi:10.5194/hessd-11-12799-2014-supplement

(C) Author(s) 2014. CC Attribution 3.0 License.

(c) (i)

\title{
Attribution of European precipitation and temperature trends to changes in circulation types
}

\author{
A. K. Fleig et al.
}

Correspondence to: A. K. Fleig (afl@nve.no) 


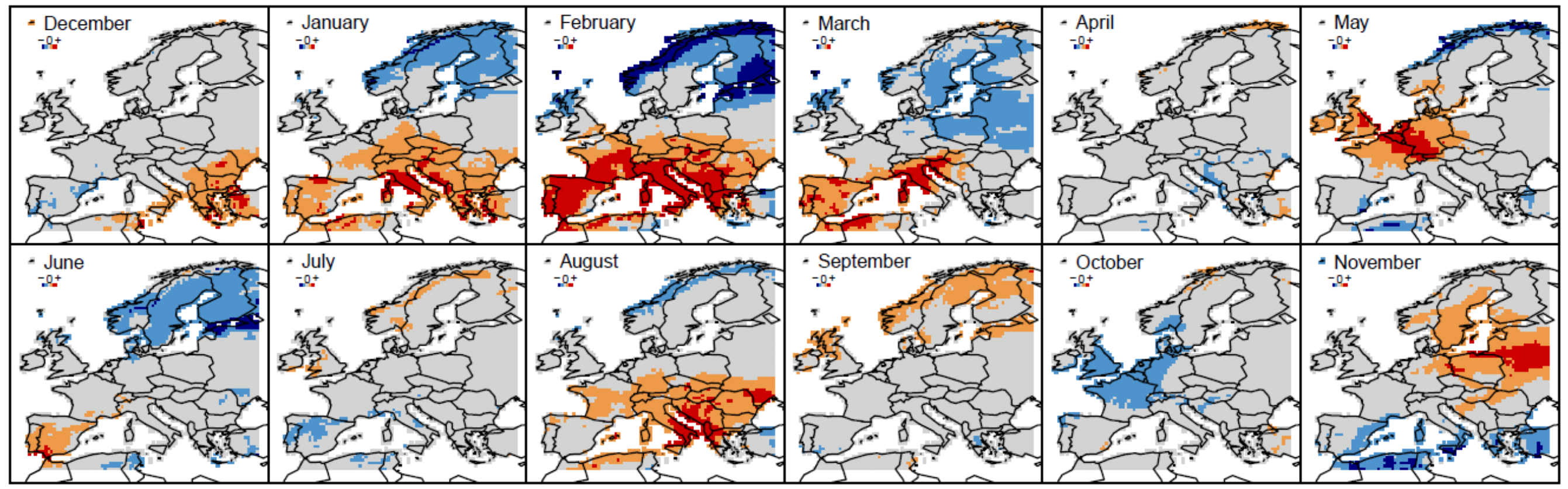

Figure S1. Monthly frequency trends in dry CTs significant at the 70\% (light colours) and 95\% (dark colours); increasing trends in red, decreasing trends in blue. 


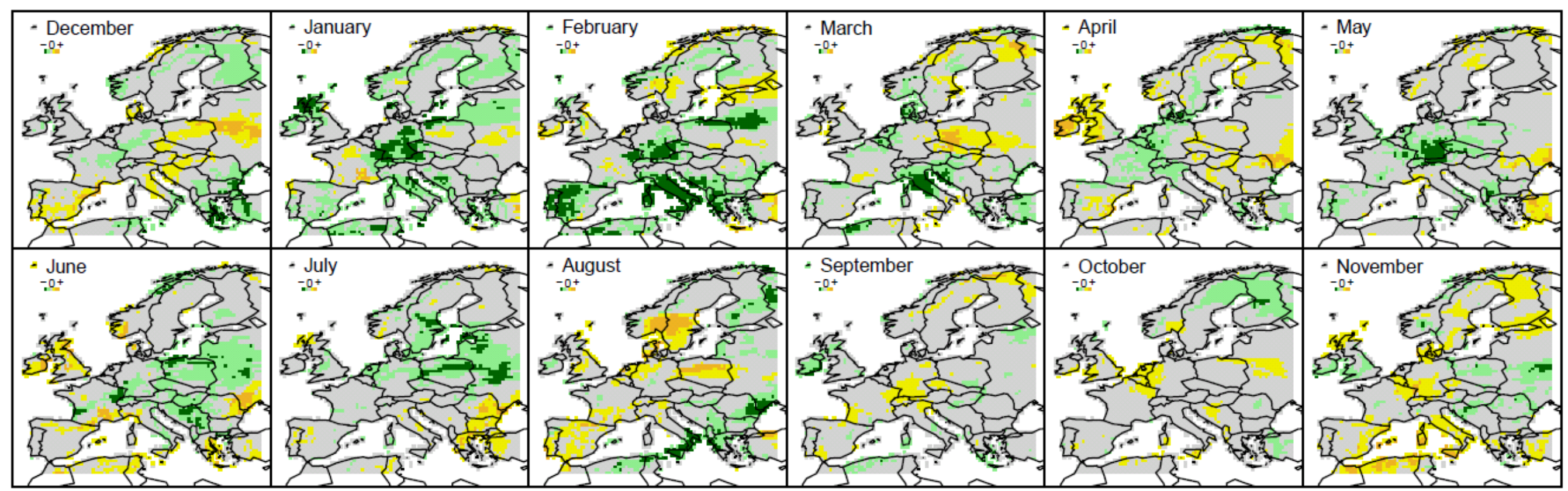

Figure S2. Monthly frequency trends in average-P CTs significant at the 70\% (light colours) and 95\% (dark colours); increasing trends in yellow, decreasing trends in green. 


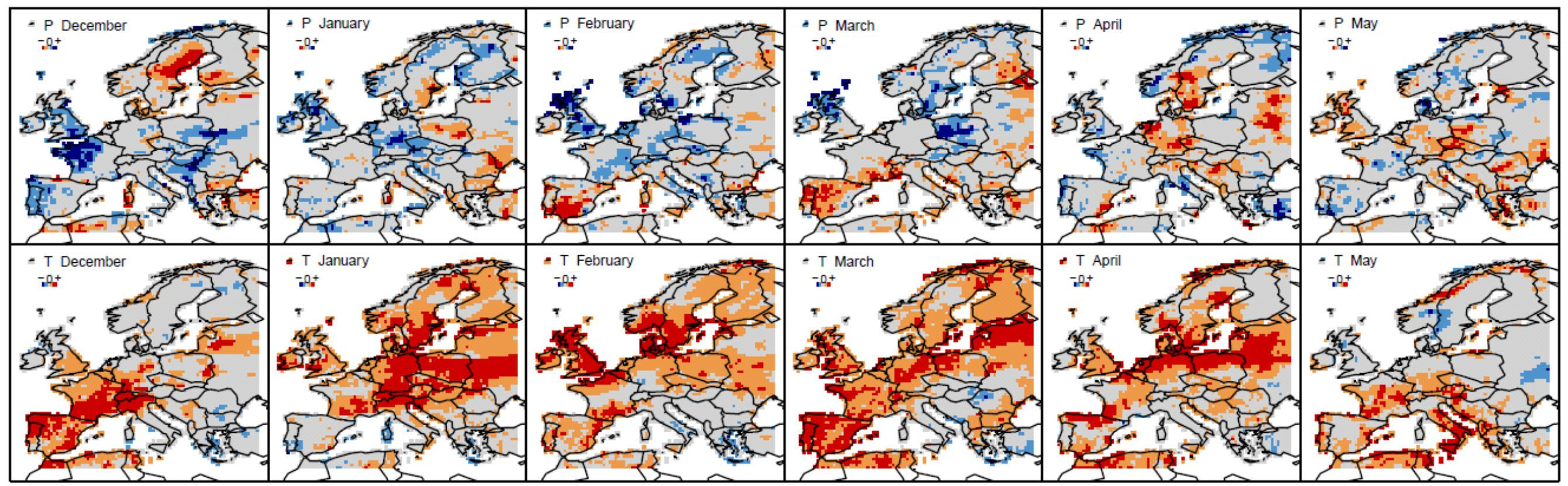

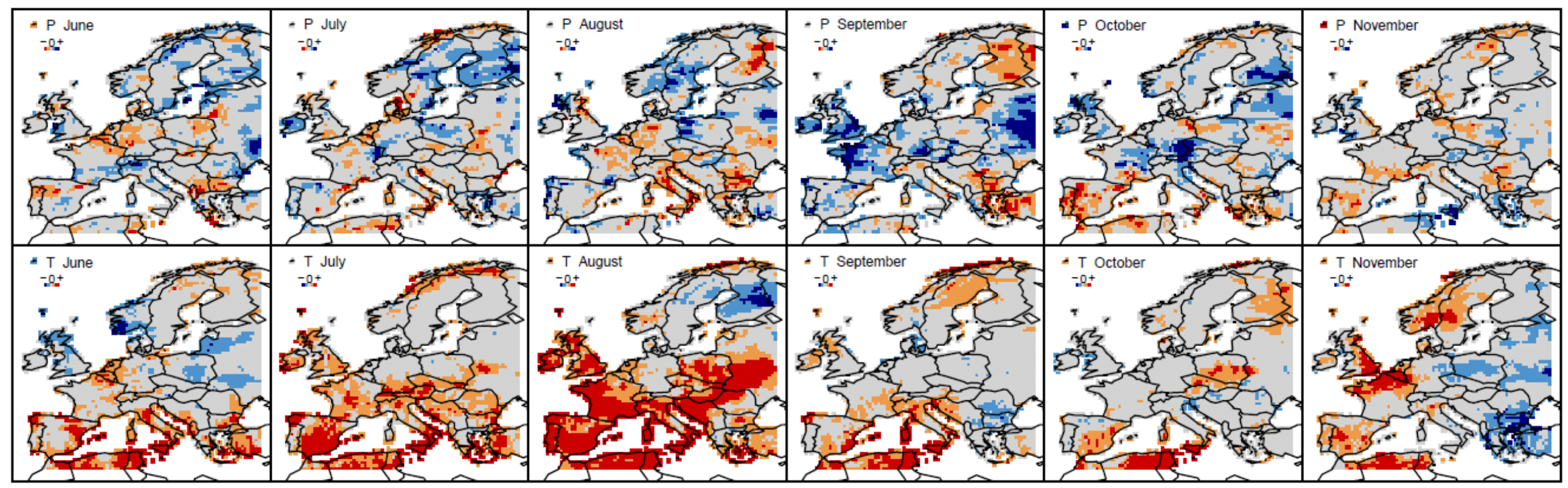

Figure S3. Monthly trends within the groups of average CTs for precipitation (rows 1 and 3) and temperature (rows 2 and 4) significant at the 70\% (light colours) and 95\% (dark colours). Precipitation: increasing trends in blue, decreasing trends in red. Temperature: increasing trends in red, decreasing trends in blue. 

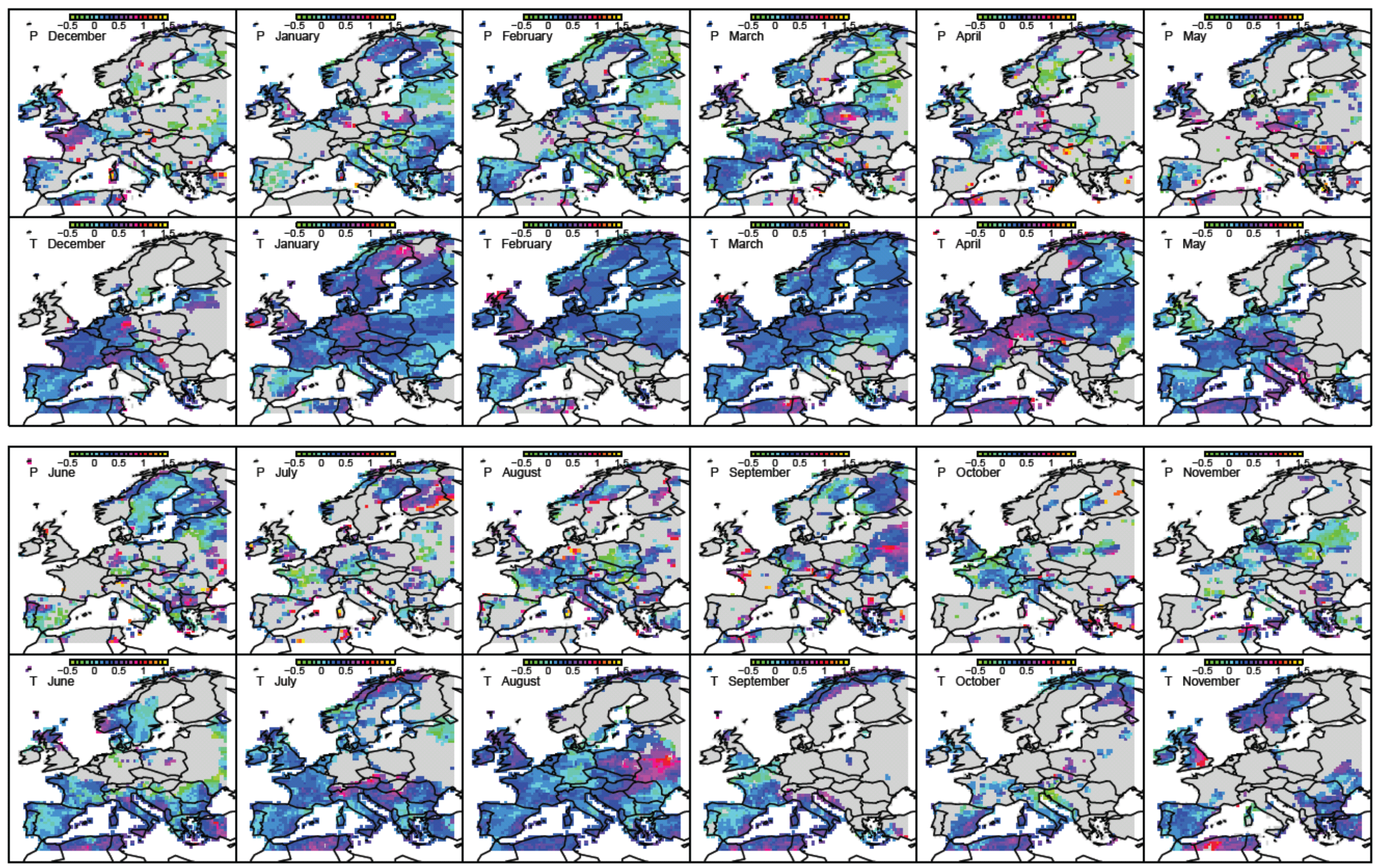

Figure S4. Monthly trend ratios for trends within the groups of average CTs for precipitation (rows 1 and 3 ) and temperature (rows 2 and 4 ). 